\title{
Holography in the high school laboratory
}

\section{Uwe Hansen, John Swez}

Uwe J. Hansen, John A. Swez, "Holography in the high school laboratory," Proc. SPIE 2525, 1995 International Conference on Education in Optics, (13 October 1995); doi: 10.1117/12.224010

SPIE Event: SPIE's 1995 International Symposium on Optical Science, SPIE. Engineering, and Instrumentation, 1995, San Diego, CA, United States 
Holography in the high school laboratory

Uwe J. Hansen and John A. Swez

Indiana State University, Department of Physics

Terre Haute, IN 47809

\begin{abstract}
$\underline{\text { ABSTRACT }}$
During the past ten years a number workshops were conducted which introduced holography into about 25 high schools in central Indiana. Sand box systems were constructed. Participants were provided with minimal equipment including a $5 \mathrm{~mW}$ laser and associated optics. Both reflection and transmission holograms were produced. The workshops included several phases. During the first phase teachers were introduced to basic principles and gained hands-on experience with their systems. During the second phase staff visits to the classes assisted teachers in implementation. During the third phase teachers brought selected students for training and review. Second year workshops utilized first year participants as workshop trainers. Workshops were concluded with a review session which included a section on curriculum design to include holography in the physics lesson planning. Continuing enthusiasm for optics and specifically holography suggests that this is a great way to generate science interest in the secondary schools. The workshops were supported with Eisenhower funds administered by the Indiana Commission for Higher Education.
\end{abstract}

Keywords: Holography, High-School laboratory, Sand-box, Teacher workshops, Reflection Hologram, Transmission Hologram.

\title{
1. INTRODUCTION AND BACKGROUND
}

Local cooperative efforts with a number of high school physics teachers over a period of several decades strongly suggested a need for the inclusion in the curriculum of topics with a certain "glamour appeal". Such topics could add to the excitement of the course and generate enthusiasm for science on the part of students. "Glamour" alone, however, is not sufficient. It is essential that the material be accessible to the students, both conceptually and in the setting of a hands-on laboratory. The excitement is directly coupled to student participation. Personal experience with holographic interferometry as a research tool in musical acoustics, and many discussions with local high school physics teachers culminated in the workshop programs discussed in this paper. 
Holography presents all the proper credentials for a topic to bring vitality to a curriculum. Hallway exhibits attract students to physics classes; making holograms is fun; students feel a sense of pride in their own holograms; furthermore, this will likely be the first time for most students to participate personally in a process still in development. Most other exciting physics discoveries are either so exotic that students only read about them in Time magazine; and then multi-million dollar laboratories staffed by armies of workers make them so remote that they are not quite real, or alternatively they have been brought into the student laboratory as historically significant discoveries of a long bygone era.

The following sections of this paper outline the steps taken to bring this exciting topic to the students. This includes obtaining financial support with Title II (later Eisenhower) funds from the Indiana Commission on Higher Education, topical preparation for teachers, equipment purchased for participating schools, developing plans for building sand-box vibration isolation tables, workshop contents and schedules, utilization of support personnel, follow-up visits to schools, and examples of holograms produced. Some comments about long range effects are included in a summary review.

\section{FINANCIAL SUPPORT}

The State of Indiana had chosen to administer DOE Title II funds through the Commission on Higher Education. Some of these funds were designed to encourage Universities to assist in strengthening science curricula at all levels in the primary and secondary schools. Only small equipment components were approved if they were essential to the overall program improvement projected. The Indiana State University Physics Department developed two successive holography proposals, both of which were approved. Total budgets, including some internal matching funds, were just over $\$ 35,000$ for the first year and $\$ 37,000$ for the second year. This provided support for 11 teachers during the first year and 18 teachers during the second year. Included in that support was funding for some minimal equipment, such as a $5 \mathrm{~mW}$ laser, a spatial filter and several lenses and mirrors, tuition and peripheral expenses for participating teachers and some support for the workshop faculty.

\section{TOPICAL PREPARATION FOR TEACHERS}

During early preliminary discussions with prospective participating teachers it became evident that the optics preparation of many teachers was either outdated or non-existent. With that in mind it was determined that the course material needed to include some introduction to modern quantum optics along with principles of coherent imaging. The topical outline 
listed below was followed during the more theoretical portion of the workshop sessions:

1. Review of geometrical optics

Reflection

Refraction

Image formation by lenses

2. Review of physical optics

Wave nature of light

Interference

Diffraction

Coherence

3. Introduction to quantum optics

Energy levels of atoms

Absorption

Electromagnetic radiation

4. Fundamentals of LASERS

Metastable states

Population inversion

Stimulated emission

5. Basic holography

Interference of two coherent beams

Image recording

Image reconstruction
6. Practical considerations

Beam control

Mirrors

Spreading lenses

Spatial filters

Coherence length

Reference beam length

Object beam length

Relative beam intensities

Exposure time

Vibration isolation

Film processing

Photographing the holographic image

7. Specialized holographic processes

Multiple holograms

$360^{\circ}$ holograms

Reflection holograms

White light holograms

Speckle interferometry

Real-time holographic interferometry

Time-average holography

8. Applications of holography

Art images

Industrial stress analysis

Non-destructive testing

Acoustical mode studies

Medical applications 


\section{HOLOGRAPHY EQUIPMENT}

The program included sufficient funding to provide each participating teacher with the following equipment:
1. $5 \mathrm{~mW}$ laser
2. spatial filter
3. 2 double concave lenses
4. 2 mirrors
5. 1 beam splitter ( $1 / 4$ in plate glass)
6. Holographic film
7. processing chemicals
8. Holography handbook
9. Laboratory manual

Mirrors and lenses are cemented to PVC tubing with epoxy cement. This facilitates use in a sand box. Oversized hose clamps are used to fasten the laser to two pieces of PVC tubing for positioning in the sand box. The film holder consists of a $4 "$ x 5 " piece of glass which is cemented with epoxy to a $1 / 2$ " aluminum rod, which in turn is inserted at both ends into pieces of PVC tubing. Large size spring-backed paper clips are used to sandwich the film between the film holder and a second piece of glass of the same size.

\section{VIBRATION ISOLATION}

Relative phase stability between reference and object beams during exposure is essential for successful holography. Lack of early success in making holograms in a high school setting can be very discouraging, leading to student disenchantment. Two things are crucial in this context. One is the physical location of the holography room. Building vibrations make any location above the ground floor marginal. It is essential that high school teachers attempting to have students make holograms identify a room which can be darkened in the basement or on the ground floor of the building. Since many schools are single floor buildings, this is usually not an insurmountable problem. Since emulsions used for holography have a very fine grain requirement, they are usually relatively insensitive, this means that total darkness is not crucial. Most classrooms can be darkened sufficiently to make them suitable for class holography work. Where that is not an option, some storage closet has been found to locate the holography table. In that setting processing chemical are wheeled in on a cart, and some large bucket is used for rinse water. The second critical element is the vibration isolation table itself. The figure below illustrates the basic design of a sand-box. A 10" deep 
3'x2' box filled with clean silica sand provides adequate mass for isolation purposes. Optical elements are cemented with epoxy to PVC tubing. The tubing is cut at a steep angle to facilitate placement in the sand. The entire box rests on four small tractor inner tubes which are partially inflated to provide soft isolation from the floor. These rest on a sheet of plywood supported by cinder blocks. Construction plans for the sand box were given to each participating teacher. The construction task was left to the teachers and their students.

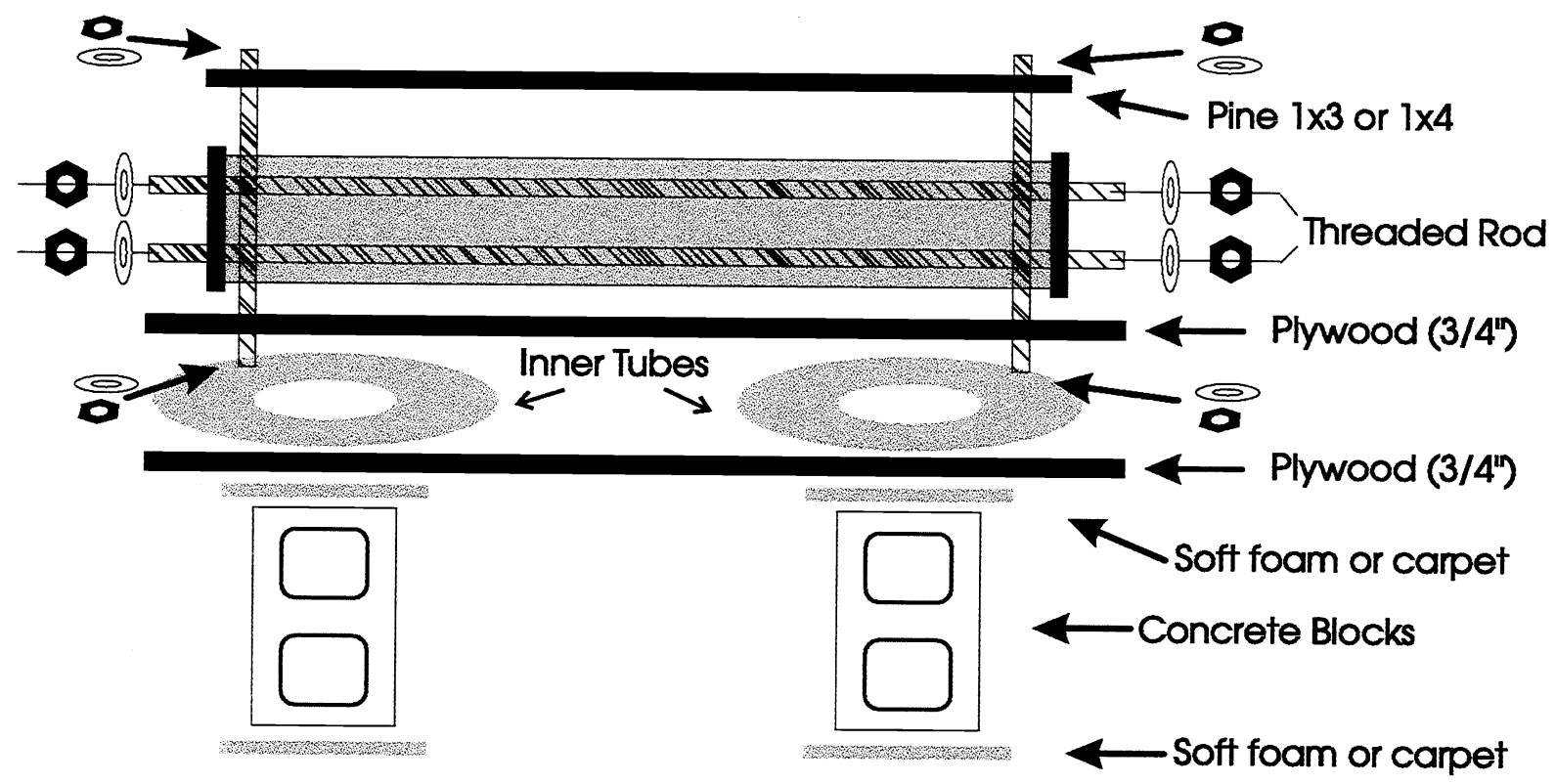

Fig. 1. Construction diagram of sand-box vibration isolation system

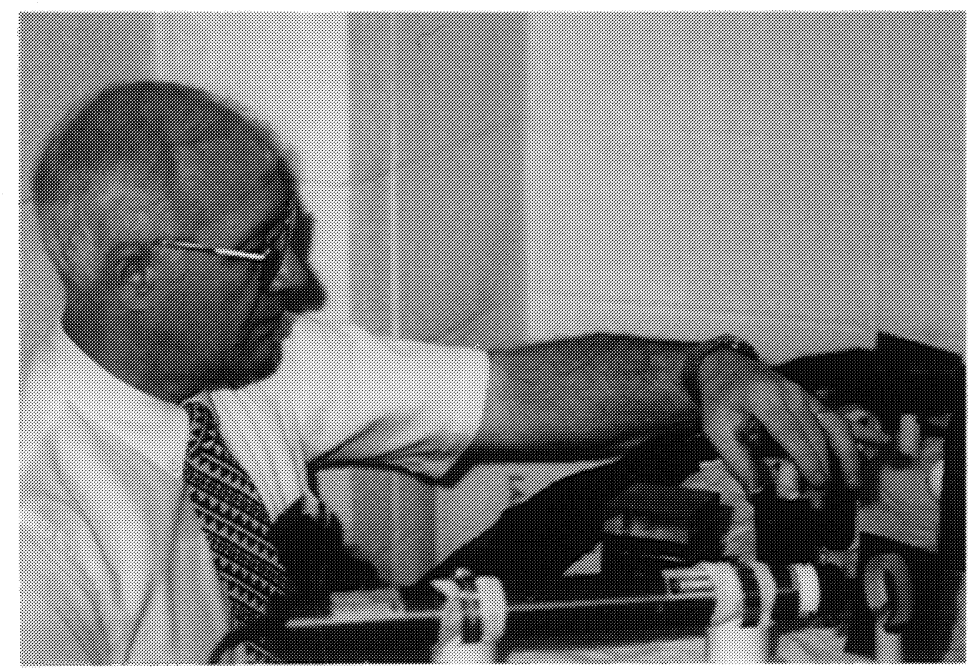

Fig. 2. Mr. Bernard Ridens, Vigo County Schools Science Supervisor and workshop participant adjusts lens in sand-box. 


\section{WORKSHOP CONTENT AND SCHEDULES}

The year long workshop program included four phases. The program began in the Fall with five successive Wednesday evening workshop sessions. By the end of those sessions teachers had enough theoretical background to understand basic holography principles along with enough practical experience to venture out on their own. Each had made several holograms by this time, and each had received the project equipment along with appropriate manuals and written instructions.

It was the task of the teachers in this second phase, during the winter and early spring, to build the sand box and introduce the program to their classes. During that time workshop staff visited each of the participating teachers in their classes and assisted with set-up and general program implementation.

In the third phase, during the early spring (March) all teachers returned for two sessions of review, problem solving and more hands-on experience in making holograms. These sessions were conducted on a more intimate basis with only half of the teachers coming for one particular session. However, each teacher brought several of their better students, and students worked together using university equipment to gain experience which would help them in making their own classroom efforts more successful. At the same time the small teacher group worked more intensely to iron out problems encountered in their own setting and to gain additional experience.

The last phase consisted of a final review session held just before school ended in the spring. Discussions in that session were built mostly around curricular questions to assist in changing existing class structures to include a unit on holography on a permanent basis.

Each of the initial five workshop sessions started with a one and a half hours theoretical session with the content as outlined previously. The subsequent half hour light catered dinner provided a nice opportunity for easy interactions. This was followed by an hour and a half of hands-on holography. Experiences during that time involved the following:

Setting up optical instrumentation

Beam leveling

Spatial filter adjustment

Path lengths adjustment

Elimination of stray room light
Beam splitting

Beam spreading

Relative beam intensity control 
Preparing Chemicals

Developer

Bleach

Making and viewing holograms

Load film holder in total darkness

Expose

Process

View

These procedures were carried out both with research quality equipment, and with the equipment provided to the teachers by the project using a sand-box of the design projected for their own class room use.

\section{PERSONNEL UTILIZATION}

A particular feature of the implementation approach for these workshops included using first year participants to assist in instruction for second year participants. During the second round of workshops, those teachers who had successfully implemented a holography segment in their curriculum as a result of their participation the previous year, served as laboratory instructors. This proved particularly helpful, both to these laboratory instructors and to the teachers in their first exposure to holography. This teaching opportunity served as a refresher for the teachers, at the same time it facilitated anticipating difficulties for the new teachers. Problems encountered by the first year teachers were discussed from the very beginning with the teachers in the second year workshop.

\section{SCHOOL VISITS}

Effectiveness in implementing a successful holography program in high schools is largely dependent on follow-up visits to schools on the part of the workshop faculty. Confidence of the local teacher is an essential element for success in making good holograms. In most cases eight workshop sessions are insufficient to communicate the depth of topical comprehension necessary for that kind of confidence. Reinforcement by personal visits is vital. A wonderful fringe benefit from that type of follow-up visit is an ongoing working relationship with a local school which can pay off in excellent students in future years. 
As a part of our school visiting program we developed a portable holography system. It includes a table top darkroom, which permits the making of a reflection hologram in a classroom setting. The set-up is made as a demonstration, it is subsequently covered, and an attached photographic changing bag provides access to the chamber for film loading and processing. A schematic diagram of the arrangement is shown..

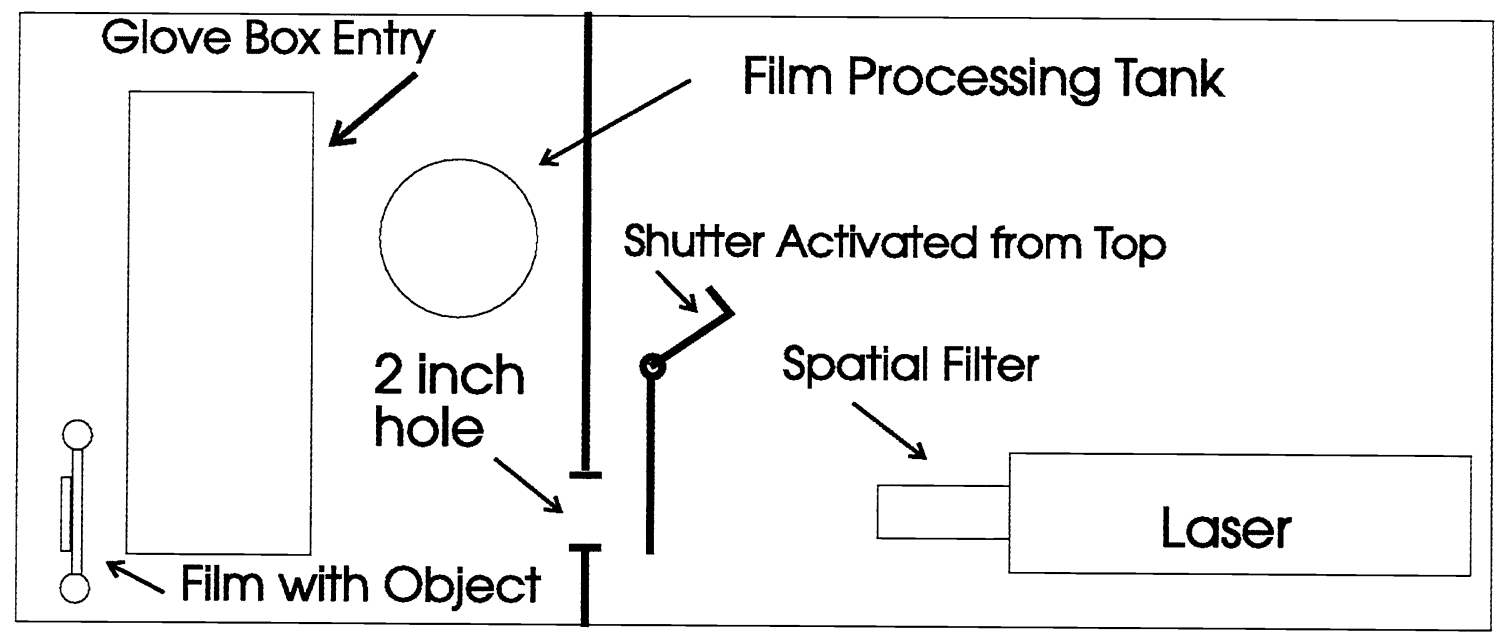

Fig. 3. Layout of demonstration reflection holography table

\section{EXAMPLES OF HOLOGRAMS}

During the course of the workshops both reflection and transmission holograms were made. The reflection holograms are somewhat less contrasty and more difficult to reproduce, consequently only photographs of transmission holograms are reproduced here.

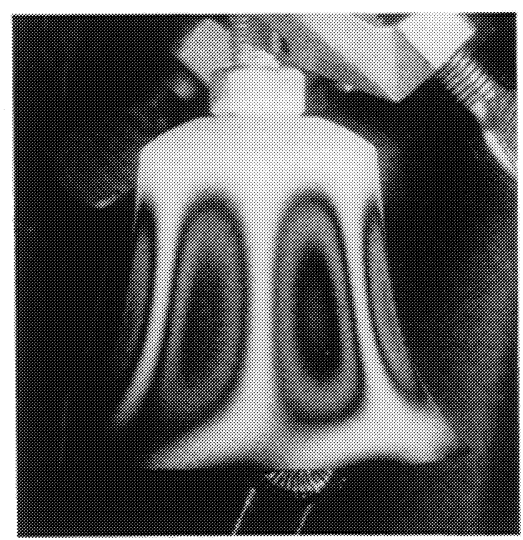

Fig. 4. Time average holographic interferogram of hand bell, visualizing one of the normal modes of vibration.

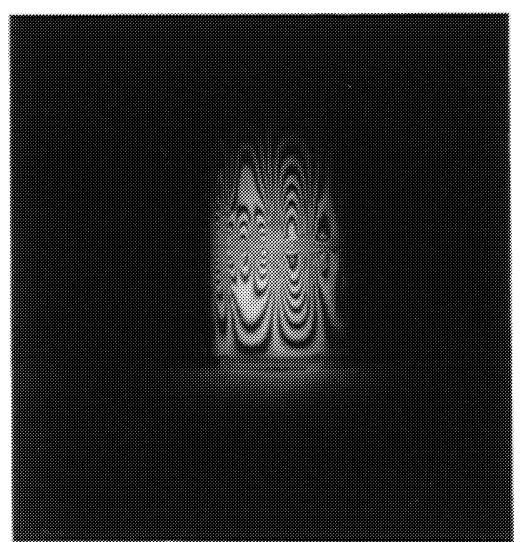

Fig. 5 Double exposure hologram of a can stressed by a rubber band. The interference pattern results from the small displacement caused by the rubber band. 


\section{SUMMARY}

The overall impression left by these workshops is that it is possible to infuse a sense of excitement into a physics class with this contemporary tool. Now, almost ten years after the first introduction of the concept, several classes are still making holograms regularly, treating it as the high point of their physics experience. In turn the physics department at Indiana State University has used holography as a major element of its annual summer honors program for high school juniors, and it has been included in summer workshops for physics high school teachers at Northern Illinois University. 